\title{
Enhancement of On-grid PV System under Irradiance and Temperature Variations Using New Optimized Adaptive Controller
}

\author{
Othman A.M.Omar ${ }^{1}$, Niveen M. Badra ${ }^{2}$, Mahmoud A. Attia ${ }^{3}$ \\ ${ }^{1,2}$ Department Physics and Engineering Mathematics, Faculty of Engineering, Ain Shams University, Egypt \\ ${ }^{3}$ Department of Electrical Power and Machines, Faculty of Engineering, Ain Shams University, Egypt
}

\begin{tabular}{|c|c|}
\hline Article Info & ABSTRACT \\
\hline Article history: & Solar Energy is one of the key solutions to future electrical power generation. \\
\hline Received Sen 172017 & Photovoltaic Plants (PV) are fast growing to satisfy electrical power demand. \\
\hline $\begin{array}{l}\text { Recerved sep 1/, 2017 } \\
\text { Revised Jan 24, } 2018\end{array}$ & Different maximum power point tracking techniques (MPPT) are used to \\
\hline & maximize PV systems generated power. In this paper, on grid PV system \\
\hline Accepted Feb 15, 2 & $\begin{array}{l}\text { model in MATLAB SIMULINK is tested under sudden irradiance and cell } \\
\text { temperature variations. Incremental Conductance MPPT is used to maximize }\end{array}$ \\
\hline Keyword: & $\begin{array}{l}\text { generated power from the PV system with the help of new adaptive } \\
\text { controller to withstand these heavy disturbances. The new adaptive controller }\end{array}$ \\
\hline Adaptive controller & is tuned for optimal operation using two different optimization techniques \\
\hline Incremental conductance MPPT & (Invasive weed and Harmony search).Optimization results for the two \\
\hline Optimization technique & to withstand different random irradiance and cell temperature patterns \\
\hline Photovoltaic systems & without failure to track the maximum power point.Finally, a brief \\
\hline & $\begin{array}{l}\text { comparison is made with a previous literature and the new adaptive } \\
\text { controller gives better results. }\end{array}$ \\
\hline
\end{tabular}

Copyright (C) 2018 Institute of Advanced Engineering and Science. All rights reserved.

\section{Corresponding Author:}

Othman A. M. Omar,

Department of Physics and Engineering Mathematics Department,

Faculty of Engineering, Ain Shams University,

Abdo Basha square, Abbassia, Cairo11517, Egypt.

Email: Osman_ahmed@eng.asu.edu.eg

\section{INTRODUCTION}

Electrical power generation map will change in the near future with lower environmental emissions. This will be done using renewable energy resources. Dependability on these resources is more and more increased whenever their operation problems more decreased. One of these problems is high variability which caused unstable systems. Solar energy is one of the major renewable energy resources used all over the world in electrical power generation. As penetration rate of solar power generation in electrical power systems is increasing with time, system stability is become important matter to be studied. Enhancement of renewable power operation stability will enhance the overall electrical power system stability with making the best use of these sustainable and clean resources.

Electrical power generation from solar energy came in many forms; one of them is Photo Voltaic panels (PV). To maximize generated electrical power from a PV system, different maximum power point tracking algorithms (MPPTs) are used. These algorithms try to reach maximum power can be generated from the panels under valid solar irradiance and air temperature. Fractional open circuit voltage (FOC) [1], Incremental conductance(IC), Perturb and observe (P\&O)[2] and Fractional short Circuit current (FSC) are examples of MPPT algorithms [3]. To enhance dynamic operation of different MPPT algorithms and giving better PV system dynamic response under heavy disturbances (variable irradiance and temperature), different types of controllers are used. A controller is a device used to give better stability and better system response. 
Proportional-integral controller (PI) and Proportional-reference frame controller (PR) [4], Fractional order proportional-integral-derivative controller (FOPID) [5] Sliding mode control [6] and Fuzzy logic controller [7] are examples for controllers used to enhance operation of PV systems and MPPT. But these controllers need optimization to tune their gains.

Optimization techniques are different algorithms used when minimization or maximization of an objective function is required. Different optimization techniques are used to tune controller gains for optimal maximum power point tracking (MPPT). As an example, in [8] Genetic algorithm and Particle swarm algorithm are used to track the MPP .Artificial Bee Colony algorithm is used in [9] for MPPT under partial shading conditions. In [10], authors showed a comprehensive review between different MPPT techniques for PV system output power maximization. In [11], authors made a practical performance evaluation for Fuzzy logic, P\&O, Hill climbing and Incremental conductance algorithms for MPPT in a PV system. A complete comparison between IC and $\mathrm{P} \& \mathrm{O}$ algorithms is made under dynamic weather conditions in [12]. Authors of [13] made analysis of PV efficiency enhancement by using Incremental Conductance under non-linear loading conditions. A variable step modified fractional order IC technique is reported in [14] to maximize power tracking in fuel cells. Results showed better dynamic response than using default IC algorithm. Authors of [15] made simulation and experimental design of new advanced IC algorithm with variable step size for PV systems. Results showed better PV array output power response under sudden irradiance variations than using default IC algorithm. Enhancement of IC algorithm operation under partial shading is made using direct fuzzy controller in [16]. In [17], authors enhanced transient stability operation of 20 MW PV power plant by modified Proportional-Integral-IC algorithm controller and Fractional Order ProportionalIntegral-IC algorithm controller for maximum power from the plant.

In this paper, a $100 \mathrm{KW}$ grid connected PV system in MATLAB SIMULINK is adopted to withstand sudden irradiance and air temperature variations due to partial shading on the PV panels. Incremental Conductance MPPT is the algorithm used to maximize system output power. New adaptive controller is used to enhance Incremental conductance operation to prevent MPPT failure. Two different Optimization techniques (Invasive weed optimization (IWO) and harmony search algorithm (HSA)) are used to tune the designing parameters of the new controller. Different optimization techniques results are compared. A Robustness test is made to check system ability to track maximum power point under six different random irradiance patterns. Finally, the PV system in [18] is constructed to compare the new optimized adaptive controller with the used $\mathrm{P} \& \mathrm{O}$ algorithm to track the maximum power point.

\section{ON-GRID PV SYSTEM MODEL IN MATLAB}

A $100 \mathrm{KW}$ on grid PV detailed model in MATLAB SIMULINK is used. The model name is “power_PVarray_grid_det” and has connections as shown in Figure 1. The model main components are:

a. PV array: To generate $100 \mathrm{KW}$ electrical power 6 modules are connected in series to form a string and 66 strings are connected in parallel. The module used name is "Sun power SPR-305-WHT" with electrical specifications as in Table 1.

Table 1. DC Electrical Characteristics

\begin{tabular}{cc}
\hline Quantity & Value \\
\hline STC Power Rating & $305 \mathrm{~W}$ \\
PTC Power Rating & $280.6 \mathrm{~W}$ \\
STC Power per unit of area & $\left(187.0 \mathrm{~W} / \mathrm{m}^{2}\right)$ \\
Peak Efficiency & $18.7 \%$ \\
Power Tolerances & $-5 \% /+5 \%$ \\
Number of Cells & 96 \\
Nominal Voltage & not applicable \\
Imp & $5.58 \mathrm{~A}$ \\
Vmp & $54.7 \mathrm{~V}$ \\
Isc & $5.96 \mathrm{~A}$ \\
Voc & $64.2 \mathrm{~V}$ \\
NOCT & $45^{\circ} \mathrm{C}$ \\
Temp. Coefficient of Power & $-0.38 \% / \mathrm{K}$ \\
Temp. Coefficient of Voltage & $-0.177 \mathrm{~V} / \mathrm{K}$ \\
\hline
\end{tabular}

b. Boost Converter: used to take PV array output DC voltage and current and change them to another DC voltage and current values to reach MPPT. Converter has a 500 volt max operating voltage and 5 KHZ switching frequency. Converter switching pulses came from converter controller circuit (Incremental conductance algorithm+Integral regulator) 
c. Inverter: takes converter output and starts to convert DC voltage and current into AC voltage and current using 3-level bridge circuit and a Pulse Width Modulation control circuit.

d. Current Filter: To decrease total harmonic distortion in the AC current from the inverter and smooth current variations.

e. Transformer: a "100 KVA-260V/25KV" transformer is used to step up voltage to the required grid voltage.

The boost converter control circuit is modified from the default Incremental Conductance and Integral Regulator to new control circuit (Incremental conductance+Adaptive Controller (Integral Regulator+Second Order Amplifier)). The second order amplifier is connected as shown in Figure 2. The amplifier transfer function between input and output is in equation $(1,2)$. The amplifier designing variables for optimal adaptive controller tuning are charging time constant $\left(T_{h}\right)$ and discharging time constant $\left(T_{l}\right)$.

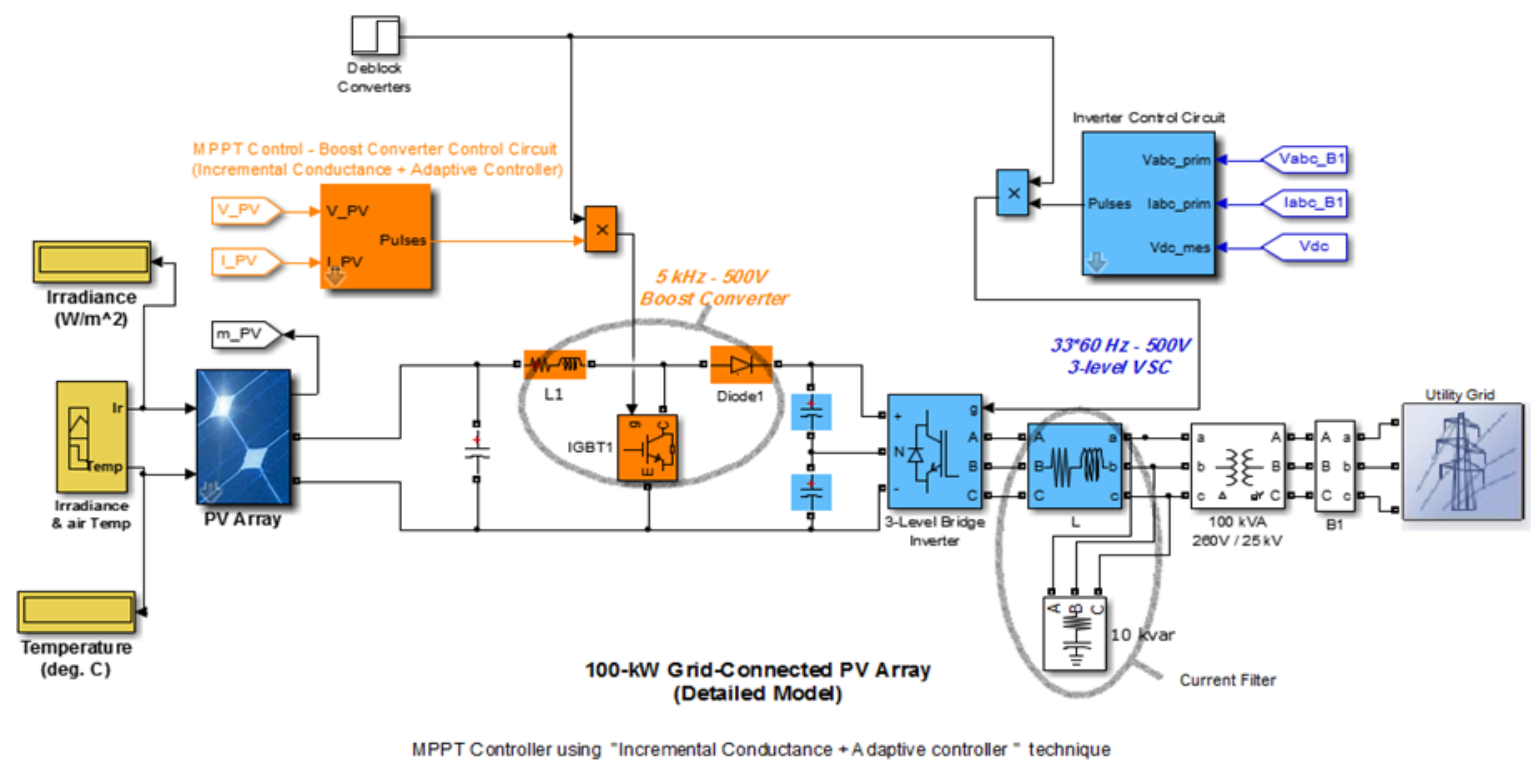

Figure 1. On-grid-100 KW PV system model in MATLAB SIMULINK

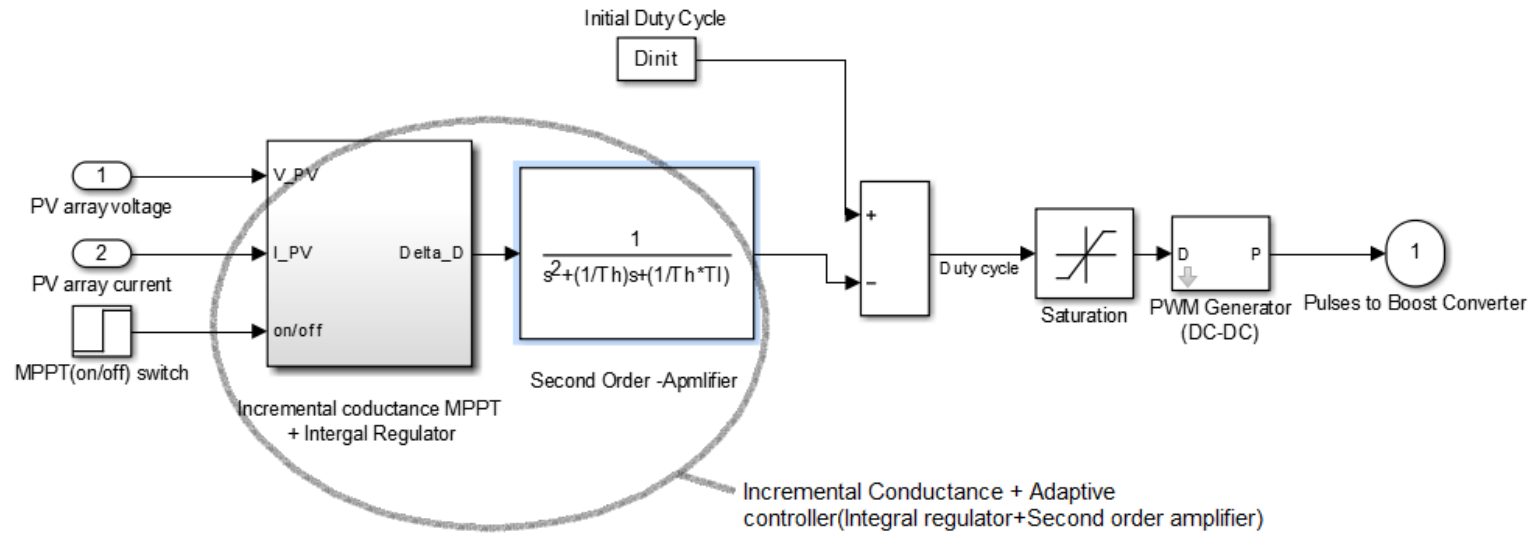

Figure 2. Boost converter control circuit with incremental conductance MPPT and adaptive controller

$$
\frac{(\text { output })}{(\text { input })}=\frac{1}{T_{h \cdot T_{l} \cdot s^{2}+T_{l \cdot s+1}}}
$$




$$
\frac{(\text { output })}{\text { (input) }}=\frac{1}{s^{2}+\frac{1}{T_{h}} \cdot s+\frac{1}{T_{h} \cdot T_{l}}}
$$

\section{OPTIMIZATION TECHNIQUES}

Two Different optimization techniques are used in this paper for PV system better performances which are Invasive Weed Optimization (IWO) and Harmony Search Algorithm (HSA).

\subsection{Invasive Weed Optimization (IWO)}

Steps of Invasive Weed Optimization technique are [19]:

a. Initializing a population: finite number of populations (seeds) is being selected with random positions. Reproduction: every seed grows to form a plant and produces newer number of seeds depending on its fitness value.

b. Spatial dispersal: The produced new seeds are being randomly dispread over the search area and grow to new plants. Randomness and adaptation in the algorithm is provided in this part. The generated seeds are being randomly distributed over the $d$ dimensional search space by normally distributed random numbers with mean equal to zero; but with variable variance. During simulation, a nonlinear alteration has shown satisfactory performance which is given in equation 3 . Where iter $_{\text {max }}$ is the maximum number of iterations, iter is the present time iteration, $\sigma_{i t e r}$ is the standard deviation at the present time step and $\mathrm{n}$ is the nonlinear modulation index.

c. Competitive exclusion: In this process maximum number of plants is reached and then the process continues until maximum iteration is reached and hopefully the plant with best fitness closest to the optimal solution is obtained.

$$
\sigma_{\text {iter }}=\frac{\left(\text { iter }_{\max }-\text { iter }\right)^{n}}{\text { iter }_{\max }{ }^{n}}\left(\sigma_{\text {initial }}-\sigma_{\text {final }}\right)+\sigma_{\text {final }}
$$

\subsection{Harmony Search Algorithm (HSA)}

Harmony Search Algorithm to maximize certain objective function has the following steps [20]:

1. Initialization

a. Setting design variables array with dimension $\mathrm{N}:\left[X_{1}, X_{2}, \ldots, X_{i}, \ldots . X_{N}\right]$

b. Set population size and $X_{i}^{j}$ is the population number "j" for the designing variable "i”; Where $j=1,2 \ldots .$. , (population size).

c. Initialize objective function $\mathrm{f}\left(X^{j}\right)$ will be maximize

d. Set each designing variable range $X_{i}^{L} \leq X_{i} \leq X_{i}^{U}$ and start with random point and dimension $\mathrm{N}$.

$$
X_{i}^{j}=X_{i}^{L}+\left(X_{i}^{U}-X_{i}^{L}\right) * \operatorname{rand}(1, N)
$$

e. Set HMCR value which is a probability function takes value between 0 and 1 .

f. Select Pitch Adjustment Rate (PAR) with ranges from 0 to 1 (PAR=1 is used).

g. Select the step size $\left(b_{i}\right)$ which is fixed or computed number ( $b_{i}=1$ is used).

h. Set iterations maximum number (used=25)

2. Initiation of Harmony Memory (HM)

$$
\mathrm{HM}=\left[\begin{array}{cccc}
X_{1}^{1} & X_{2}^{1} & \ldots & X_{N}^{1} \\
X_{1}^{2} & X_{2}^{2} & \ldots & X_{N}^{2} \\
\ldots & \ldots & \ldots & \ldots \\
X_{1}^{H M S} & X_{2}^{H M S} & \ldots & X_{N}^{H M S}
\end{array}\right](5), \quad \mathrm{F}=\left[\begin{array}{c}
f\left(X^{1}\right) \\
f\left(X^{2}\right) \\
\ldots \\
f\left(X^{H M S}\right)
\end{array}\right]
$$

3. Generation of New Harmony is based on the following criteria

a. New Harmony is selected randomly; $X^{\prime}=\left(X_{1}^{\prime}, X_{2}^{\prime}, \ldots \ldots . X_{N}^{\prime}\right)$ with a $(\mathrm{HMCR}=1)$ probability

b. Choosing probability (PAR $=1$ ) doesn't add any amount to New Harmony and New Harmony will be $X_{i}^{\prime}=X_{i}^{\prime} \pm b_{i}$

c. Worst value for the objective function is removed from harmony memory at end of iteration.

4. Repeat till maximum iteration value is reached. 


\section{OBJECTIVE FUNCTION}

The Objective function will be maximized using both optimization techniques is the delivered energy (E) to grid form the $100 \mathrm{KW}$ PV system. The delivered energy (E) is the integration of PV system delivered power to the grid (P) with time as in equation (7). Increasing the delivered energy means enhancment of incremental conductance algorithm to be stable under sudden irradiance and temperature changing patterns without failure to track the maximum power point (MPP). The designing variables for the second order amplifier to maximize delivered energy will be amplifier circuit charging time (T_h) and discharging time ( $\left.\mathrm{T}_{-} \mathrm{l}\right)$. Let $\mathrm{O}$ and $\mathrm{M}$ defined as in equation (8-9). Ranges used for $\mathrm{O}$ and $\mathrm{M}$ by the optimization techniques to maximize the objective function will be as in equation $(10,11)$. The optimization algorithms will select optimal $\mathrm{O}$ and $\mathrm{M}$ values for objective function maximization.

$$
\begin{aligned}
& E=\int_{0}^{t} P \cdot d t \quad(K W \cdot s e c) \\
& O=\frac{1}{T_{h}}\left(\sec ^{-1}\right) \\
& M=\frac{1}{T_{h} \cdot T_{l}}\left(\sec ^{-2}\right) \\
& 0.1 \leq O \leq 50 \\
& 0.1 \leq M \leq 100
\end{aligned}
$$

\section{METHODOLOGY}

Optimization techniques (IWO and HSA) general working methodology to select optimal charging time and discharging time values for optimal tuning of the adaptive controller to maximize the delivered energy (E) to the grid is shown in Figure 3.

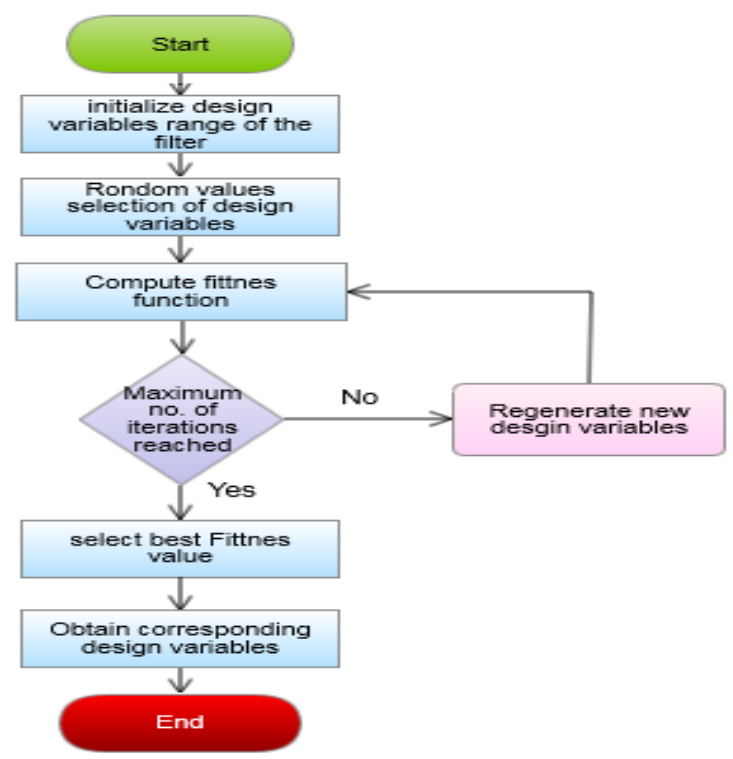

Figure 3. Flow chart of methodology

\section{SIMULATION RESULTS AND COMPARISON}

The simulation results are divided into three stages. First one is PV system response under (variable irradiance pattern-constant PV cells temperature). The second one is PV system response under (variable irradiance pattern-variable PV cells temperature). A Robustness test is carried out to check the stability of the new optimized controller. Finally; the new optimized controller is used with PV system constructed in [18] and compares its performance with the used P\&O one. 


\subsection{PV System Response Under (Variable Irradiance Pattern-Constant PV Cells Temperature)}

Irradiance pattern shown in Figure 4 is applied as an input to the PV array without taking cell temperature variations into consideration. Cell temperature is assumed constant as in Figure 5. The optimization process is made one time using invasive weed optimization algorithm and another time using harmony search algorithm to tune the gains of the optimized controller. As shown in Table 2, Invasive weed optimization algorithm gives slightly higher delivered energy (E) to the grid but taking longer optimization time. While harmony search algorithm has very lower optimization time. Figure 6 shows the PV system's delivered power to the grid after and before using optimized controller. Before using the optimized controller, power decreased to zero in the time intervals from ( $t=1.18$ to $t=1.25 \mathrm{sec}$ and $t=1.5$ to $t=1.52 \mathrm{sec})$ but by using both IWO-optimized controller and HSA-optimized controller the system continues tracking the MPP without falling to zero at these time intervals.

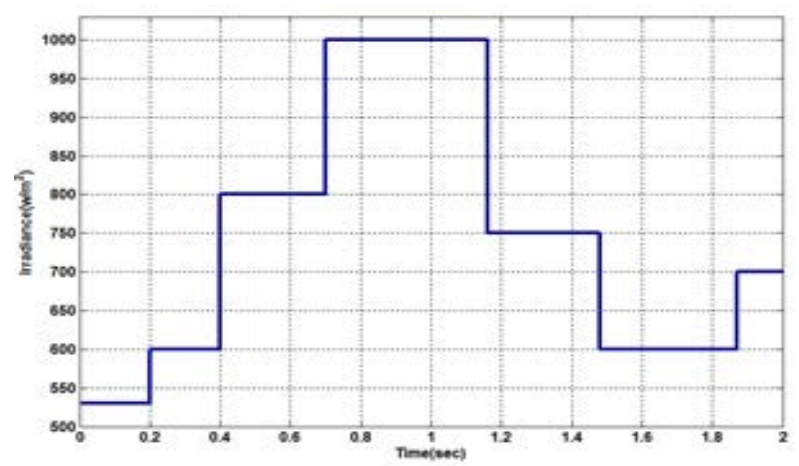

Figure 4. Solar irradiance pattern with time

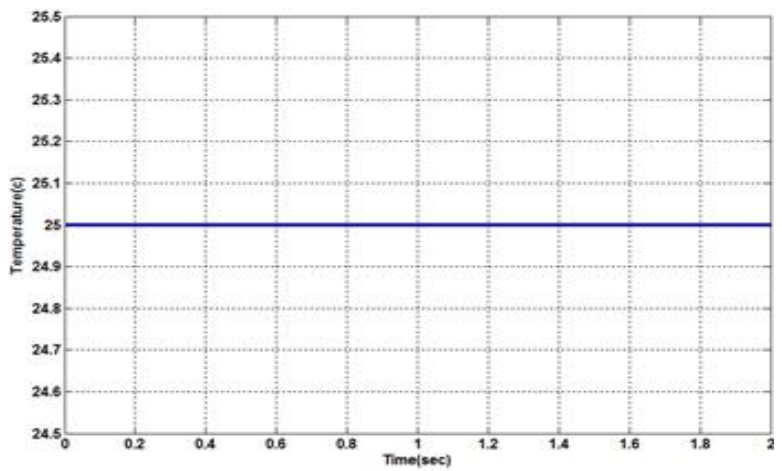

Figure 5. Constant cell temperature variations

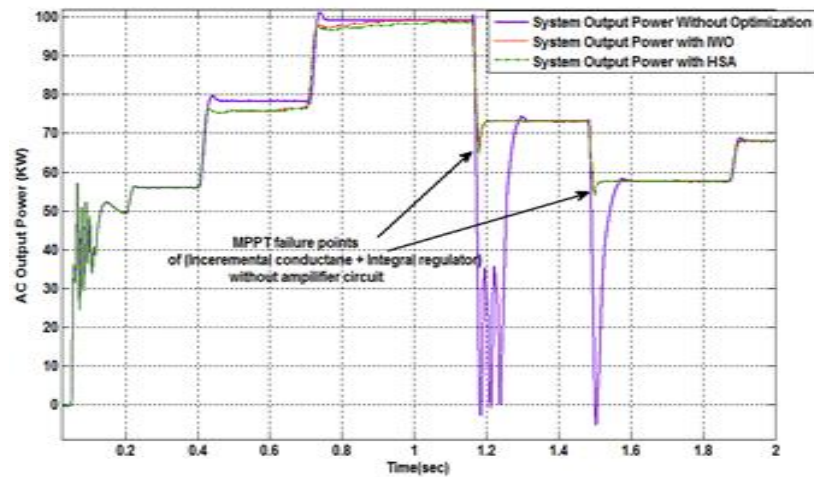

Figure 6. Delivered power to the grid with and without optimized controller 
Table 2. IWO and HSA Optimization Results for Constant Cell Temperature

\begin{tabular}{lcc}
\hline \multicolumn{1}{c}{ Optimization } & IWO & HSA \\
\hline Charging time inverse value $(O)\left(\mathrm{sec}^{-1}\right)$ & 3.004 & 9.277 \\
Multiplied charging and discharging times & 30.648 & 24.0713 \\
inverse value $(M)\left(\mathrm{sec}^{-2}\right)$ & 139.8616 & 139.5044 \\
Objective Function $(E)($ KW.sec) & 25 & 25 \\
No. of Iterations & 26.2 & 2.3 \\
Time Taken(hours) & & \\
\hline
\end{tabular}

\subsection{PV System Response Under (Variable Irradiance Pattern-Variable PV Cells Temperature)}

The optimization process is repeated again but with taking cell temperature variations into consideration. The assumed temperature pattern is seen in Figure 7. The temperature pattern is constructed within a correlation coefficient range (between irradiance and air temperature variations) as in reference [21]. As shown in Table 3, IWO also gives slightly higher objective function value (E) but with longer optimization time.HSA also has very lower optimization time. The PV system's delivered power to the grid after and before using optimized controller is shown in Figure 8.

The system before optimization failed to withstand sudden decrease in the irradiance and system output power dropped to zero in the time interval from $(\mathrm{t}=1.18$ to $\mathrm{t}=1.71 \mathrm{sec})$ but with IWO-optimized controller the system continues MPPT. HSA-optimized controller also successes to track the MPP at that time interval. However IWO gives slightly delivered energy to the grid but HSA is more robust against temperature and irradiance variations. It's cleared from the previous results that without the optimized controller there is a MPPT failure.

Table 3. Optimization Techniques Results for Variable Cell Temperature

\begin{tabular}{lcc}
\hline \multicolumn{1}{c}{ Optimization } & IWO & HSA \\
\hline Charging time inverse value $(O)\left(\mathrm{sec}^{-1}\right)$ & 4.643 & 4.464 \\
Multiplied charging and discharging & 35.252 & 26.146 \\
times inverse value $(M)\left(\mathrm{sec}^{-2}\right)$ & & \\
Objective Function( $E)(\mathrm{KW} . \mathrm{sec})$ & 138.379 & 138.299 \\
No. of Iterations & 25 & 25 \\
Time Taken(hours) & 28 & 2.5 \\
\hline
\end{tabular}

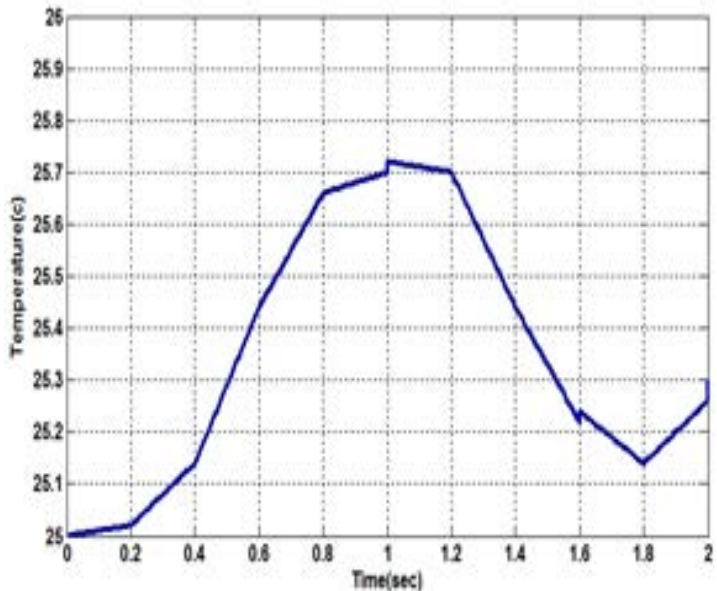

Figure 7. Variable cell temperature pattern

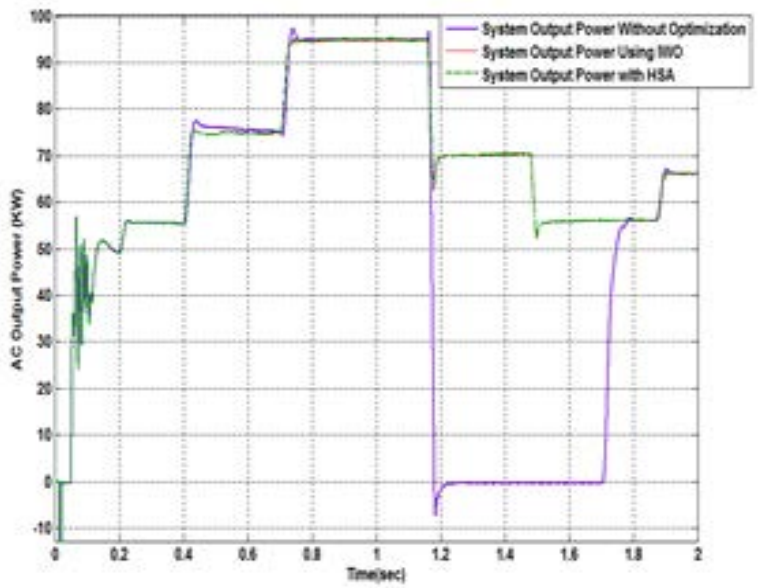

Figure 8. Delivered power to the grid with and without optimized controller with variable cell temperature

\subsection{Robustness Test}

To check the robustness of the optimized controller six random irradiance and temperature patterns are used. Patterns are applied to the system without repeating the optimization process. From Figures 9 and 10, IWO and HSA proved their reliability through keeping the system at the the MPP although the normal system without optimized controller failed in that. 


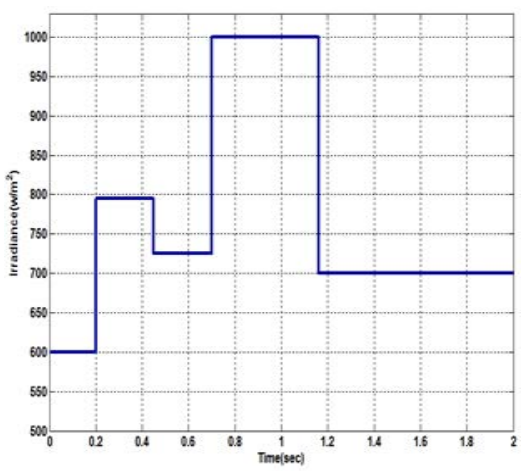

a) Irradiance Pattern 1

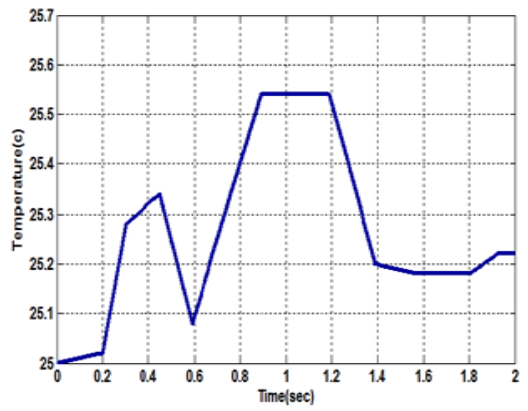

b) Temperature for Pattern 1

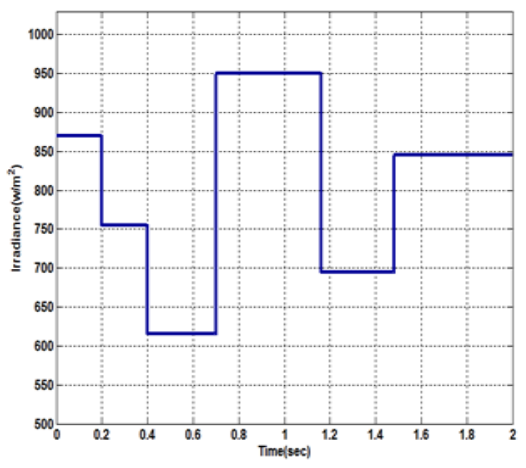

d) Irradiance Pattern 2

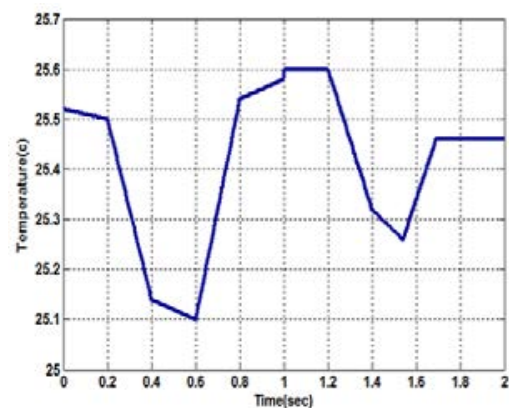

e) Temperature for Pattern 2

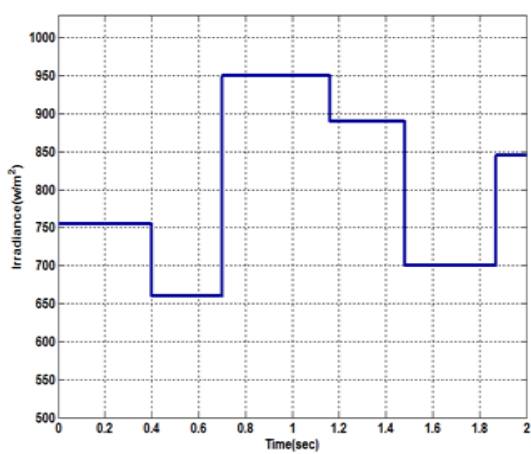

g) Irradiance Pattern 3

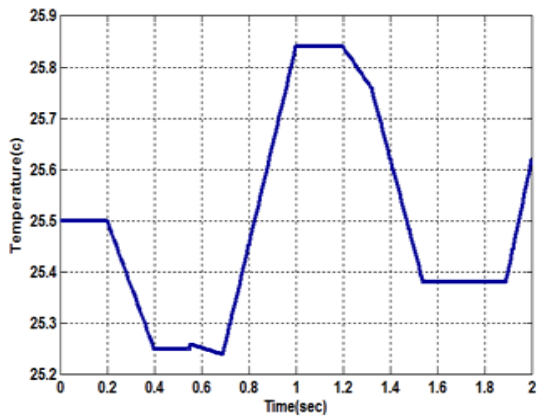

h) Temperature for Pattern 3

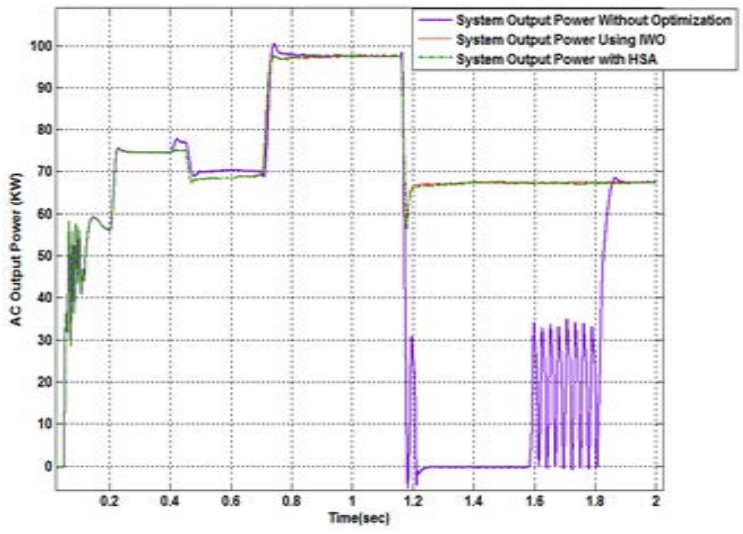

c) System Output Power Response for Pattern 1

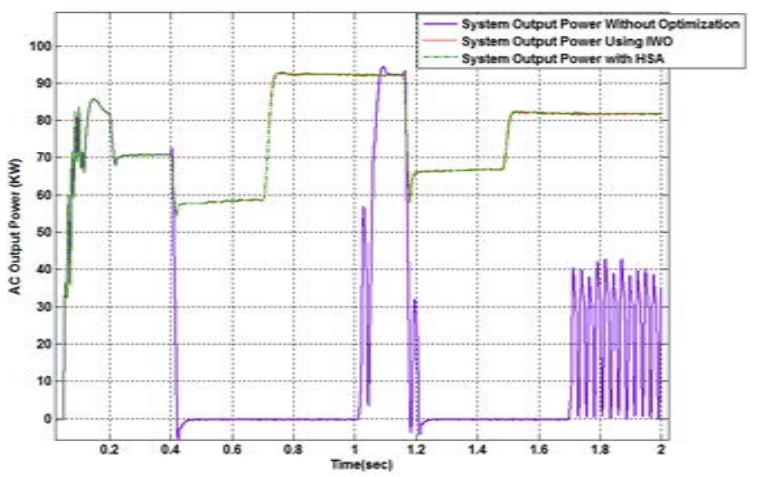

f) System Output Power Response for Pattern 2

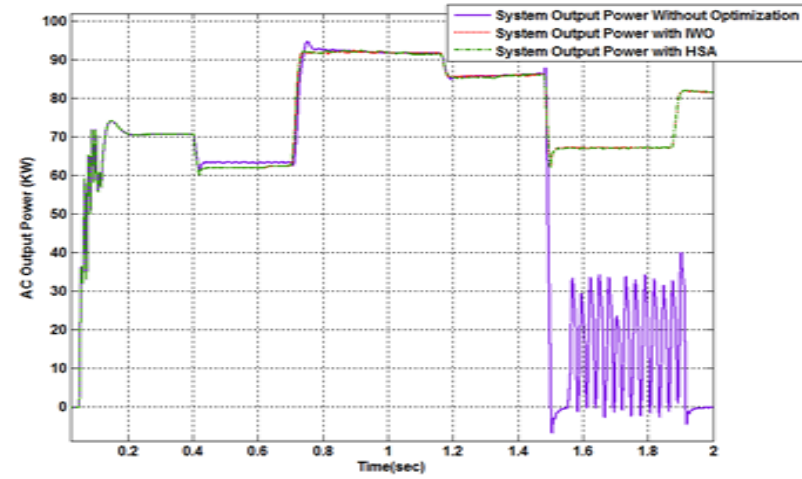

i) System Output Power Response for Pattern 3

Figure 9. Robustness test for three different irradiance patterns with corresponding temperature variation patterns 


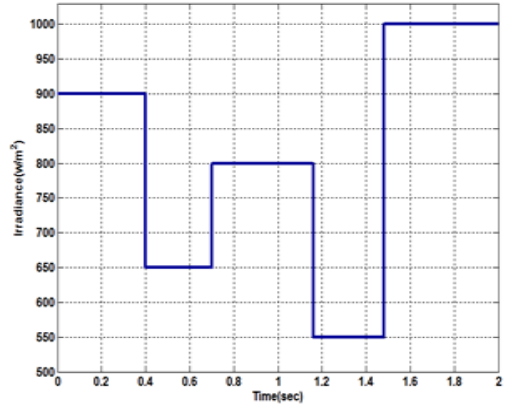

a) Irradiance Pattern 4

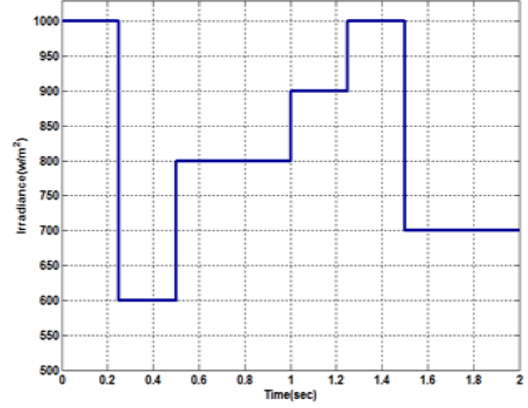

d) Irradiance Pattern 5

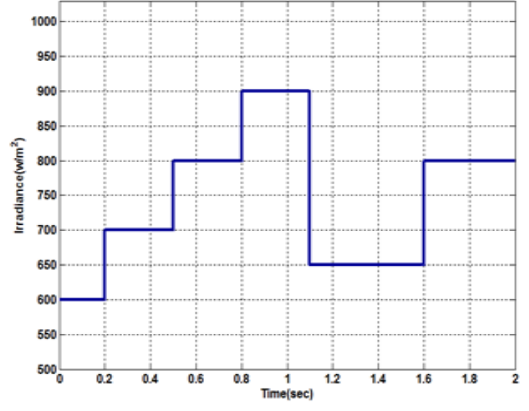

g) Irradiance Pattern 6

Figure 10. Another different three irradiance patterns with corresponding temperature patterns for more convenient

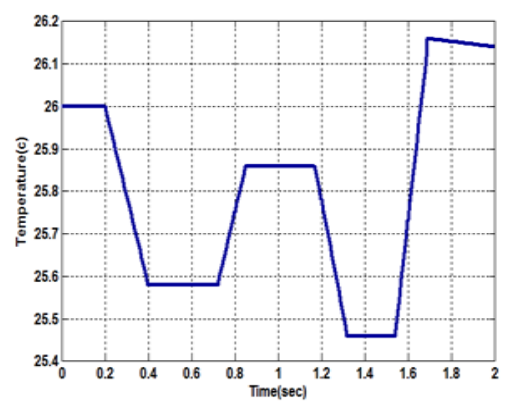

b) Temperature for Pattern 4

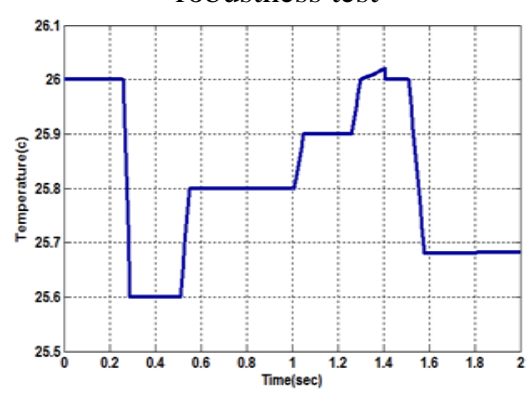

e) Temperature for Pattern 5

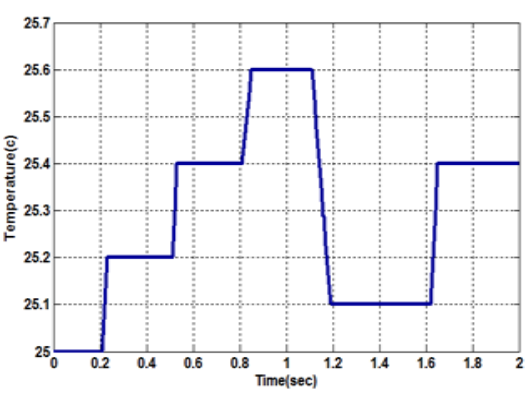

h) Temperature for Pattern 6

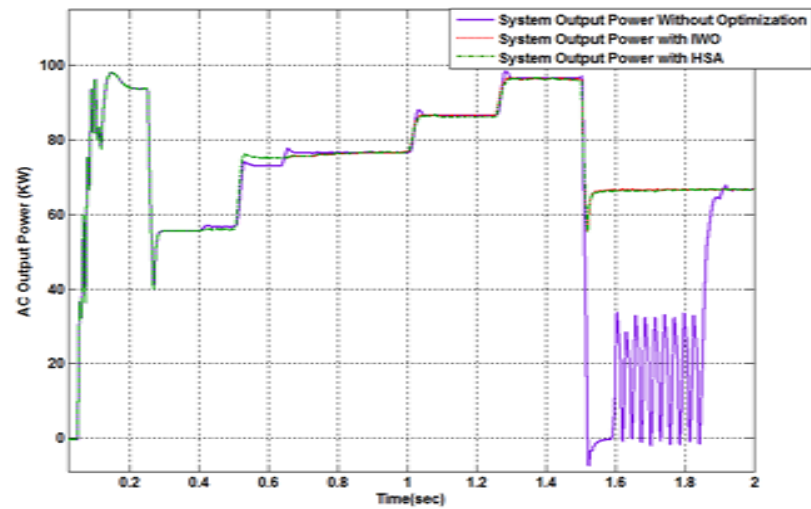

c) System Output Power Response for Pattern 4

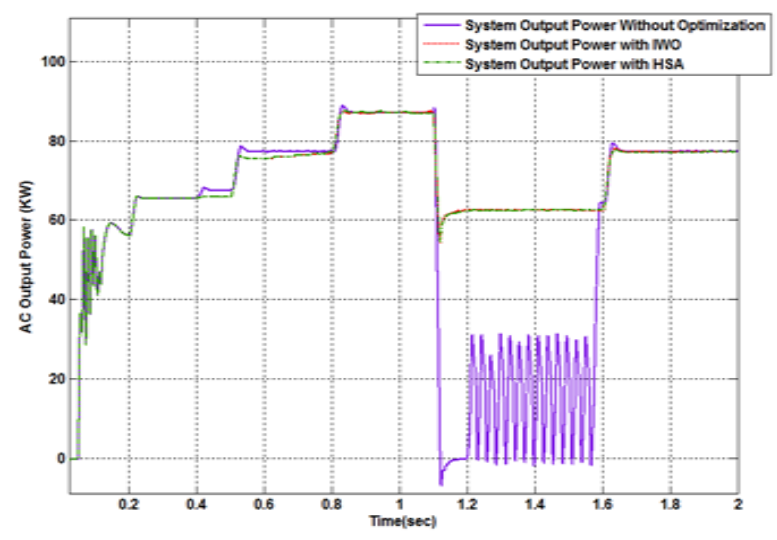

f) System Output Power Response for Pattern 5

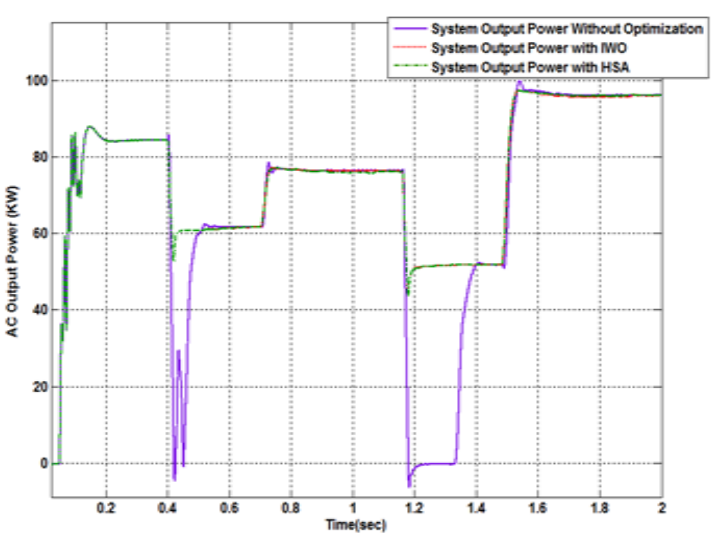

i) System Output Power Response for Pattern 6

Figure 10. Another different three irradiance patterns with corresponding temperature patterns for more convenient robustness test 


\subsection{Comparison}

In this section, the more robust technique shown in the previous results (HSA-optimized controller) will be compared with the used $\mathrm{P} \& \mathrm{O}$ algorithm in reference [18]. The PV system is constructed as in reference [18] using MATLAB/SIMULINK with two PV arrays with about $200 \mathrm{KW}$ rating. The gains were obtained in the first run optimization will be used without change to proof that the HSA-optimized controller is still reliable even with changing the PV array rating. The input irradiance for the first and the second PV array is shown in Figure 11.

The temperature is assumed constant at 25C as in [18]. The power delivered to the grid obtained in reference [18] is shown in Figure 12 while P\&O algorithm was used to track the MPP. Figure 13 shows the delivered power to the grid with the HSA-optimized controller to track the MPP. From Figures 12 and 13 the area under the curve for the delivered power of the HSA-optimized controller is higher than area under the curve of the $\mathrm{P} \& \mathrm{O}$ algorithm, so HSA-optimized controller gives higher delivered energy to the grid which means better average MPPT. Finally from the obtained results, robustness test and comparison, HSAoptimized controller proved its reliability under variable irradiance, variable temperature and variable PV rating.

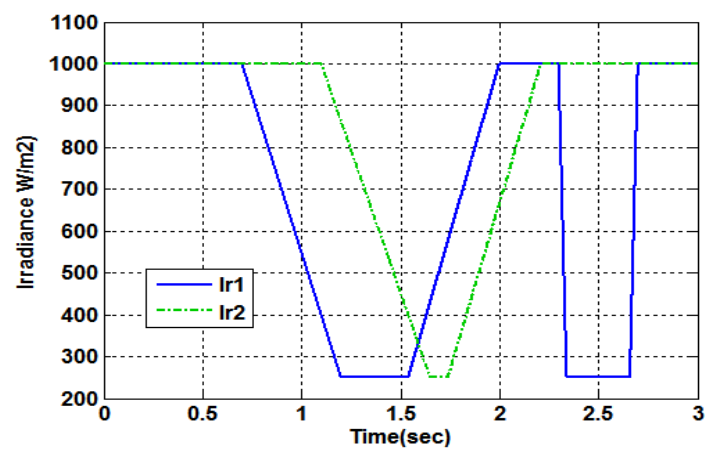

Figure 11. Irradiance patterns for array one and two

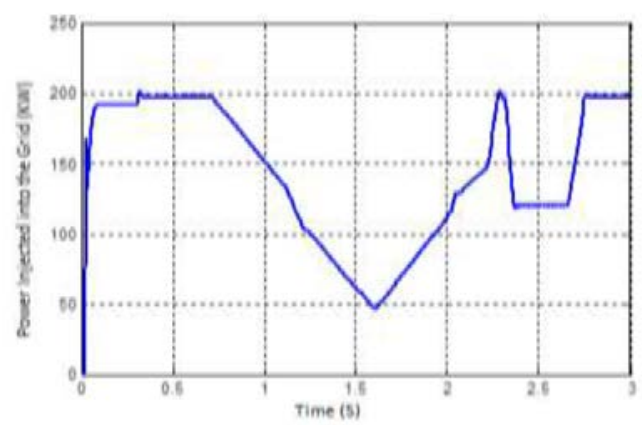

Figure 12. Delivered power to the grid using P\&O algorithm

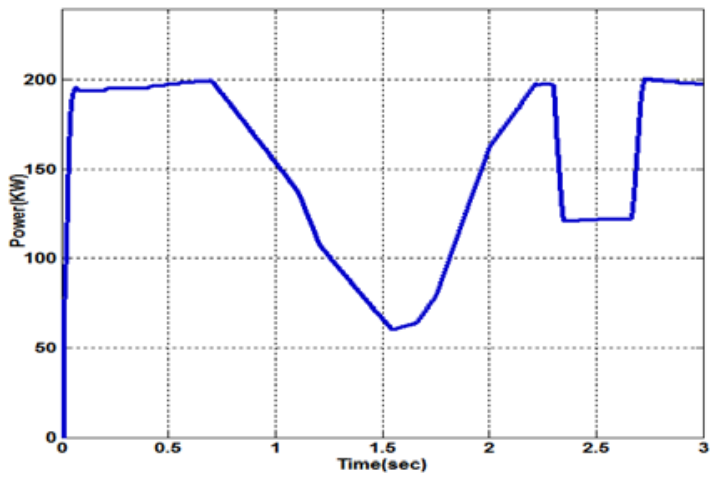

Figure 13. Delivered power to the grid using the HSA-optimized controller

\section{CONCLUSION}

Heavy sudden disturbances such as sudden irradiance changes due to partial shading and corresponding temperature variations may result in MPPT failure and make PV systems unreliable. Under different random irradiance patterns the incremental conductance with enhancement of integral regulator failed to withstand these disturbances. Using the new optimized adaptive controller consists of integral regulator and second order amplifier results in no MPPT failure so; enhancement of incremental conductance operation and more PV system reliability is achieved. After making the optimization process to tune the adaptive controller gains better results are reached. The IWO-optimized controller gives slightly higher delivered energy to the grid than The HSA-optimized controller but with longer time for optimization. The HSA-optimized controller is more robust against irradiance and temperature variations. Finally from the 
obtained results, robustness test and comparison HSA-optimized controller proved its reliability under variable irradiance, variable temperature and variable PV rating.

\section{REFERENCES}

[1] Esram T, Chapman PL., “Comparison of photovoltaic array maximum power point tracking techniques.” IEEE Transactions Energy Conversion 2007; 22:439-49.

[2] Weidong X, Elnosh A, Khadkikar V and Zeineldin, “Overview of maximum power point tracking technologies for photovoltaic power systems,” IECON 2011 - 37th Annual Conference on IEEE Industrial Electronics Society 390005.

[3] A. Zegaoui, M. Aillerie, P. Petit, J.P. Sawicki, A. Jaafar, C. Salame, J.P. Charles, “ Comparison of Two Common Maximum Power Point Trackers by Simulating of PV Generators, ”Energy Procedia, Volume 6, 2011, Pages 678687, ISSN 1876-6102,

[4] Ritesh Dash,Sarat Chandra Swain,Sanhita Mishra ," Comparative Analysis of Linear Controllers used for Grid Connected PV System ,"International Journal of Electrical and Computer Engineering(IJECE),Vol.8 ,No. 1,Feburary 2018,pp. 513-520.

[5] Vanitha D, M.Rathinakumar,"Fractional Order PID Controlled PV Buck Boost Converter with Coupled Inductor,"International Journal of Power Electronics and Drive Systems (IJPEDS), Vol. 8, No. 3, September 2017,pp. 1401-1407.

[6] Vidyasagar, Deepak Kumar Nayak, Roopam Jha, "Maximum Power Point Tracking for a Grid Connected Photovoltaic System using Sliding Mode Control,"International Journal of Power Electronics and Drive Systems (IJPEDS), Vol. 8,No. 4, December 2017,pp. 1785-1792.

[7] S. Narendiran , Sarat Kumar Sahoo ,Raja Das ,Ashwin Kumar Sahoo,"Fuzzy logic controller based maximum power point tracking for PV system,"3rd International Conference on Electrical Energy Systems(ICEES)2016,pp. 29-34.

[8] Afef Badis, Mohamed Nejib Mansouri , Anis Sakly,"PSO and GA-based maximum power point tracking for partially shaded photovoltaic systems,"7th International Renewable Energy Congress (IREC) 2016.

[9] Salmi Hassan, Badri Abdelmajid, Zegrari Mourad, Sahel Aicha, Baghdad Abdenaceur,"An Advanced MPPT Based on Artificial Bee Colony Algorithm for MPPT Photovoltaic System under Partial Shading Condition,"nternational Journal of Power Electronics and Drive Systems(IJPEDS),Vol. 8,No. 2, June 2017,pp. 647-653.

[10] J. Prasanth Ram, T. Sudhakar Babu, N. Rajasekar, "A comprehensive review on solar PV maximum power point tracking techniques, ” Renewable and Sustainable Energy Reviews, Volume 67, 2017, Pages 826-847.

[11] Hassan Abouobaida, EL Beid Said ,"Practical Performance Evaluation of Maximum Power Point Tracking Algorithms in a Photovoltaic System,"International Journal of Power Electronics and Drive Systems (IJPEDS),Vol. 8,No. 4, December 2017,pp. 1744-1755.

[12] Kashif Ishaque, Zainal Salam, George Lauss, "The performance of perturb and observe and incremental conductance maximum power point tracking method under dynamic weather conditions, Applied Energy,” Volume 119, 2014, Pages 228-236.

[13] P. Sivakumar, Abdullah Abdul Kader, Yogeshraj Kaliavaradhan, M. Arutchelvi, “ Analysis and enhancement of PV efficiency with incremental conductance MPPT technique under non-linear loading conditions,” Renewable Energy, Volume 81, 2015, Pages 543-550.

[14] Pi-Yun Chen, Kuo-Nan Yu, Her-Terng Yau, Jun-Ting Li, Chih-Kang Liao, "A novel variable step size fractional order incremental conductance algorithm to maximize power tracking of fuel cells, Applied Mathematical Modelling,” Volume 45, 2017, Pages 1067-1075.

[15] Abdelhamid Loukriz, Mourad Haddadi, Sabir Messalti, “ Simulation and experimental design of a new advanced variable step size Incremental Conductance MPPT algorithm for PV systems,” ISA Transactions, Volume 62, 2016, Pages 30-38.

[16] Tawfik Radjai, Lazhar Rahmani, Saad Mekhilef, Jean Paul Gaubert, "Implementation of a modified incremental conductance MPPT algorithm with direct control based on a fuzzy duty cycle change estimator using dSPACE," Solar Energy, Volume 110, 2014, Pages 325-337.

[17] Rania Gamal Mohamed, Mohamed Ahmed Ebrahim, Fahmy Metwally Bendary and Saied Abd ALAziz Osman,“Transient Stability Enhancement for 20 MW PV Power Plant via Incremental Conductance Controller,” International Journal of System Dynamics Applications (IJSDA), Vol. 6, Issue 4,2017.

[18] Omar Mohammed Benaissa, Samir Hadjeri, Sid Ahmed Zidi," Modeling and Simulation of Grid Connected PV Generation System Using Matlab/Simulink,"International Journal of Power Electronics and Drive Systems (IJPEDS), Vol. 8, No. 1, March 2017, pp. 392-401.

[19] Mehrabian, Ali Reza, and Caro Lucas. "A novel numerical optimization algorithm inspired from weed colonization. ” Ecological informatics 1.4 (2006): 355-366.

[20] Z. W. Geem, J. H. Kim, and G.V.Loganathan, "A new heuristic optimization algorithm: Harmony search," Simulation, Vol. 76, no. 2, pp. 60-68, 2001.

[21] Knut Makowsk, “The daily temperature amplitude and surface solar radiation,” University of Zurich ,Doctoral degree book,chapter 3. 